\title{
To Our Readers and the AES Membership:
}

Epilepsy Currents is now entering its 11 th year of publication as the official journal of the American Epilepsy Society. We feel that the format of commentaries on important recent publications and reviews of clinical and basic science topics of interest has been very successful, and we owe this success to our contributing editors and invited reviewers who understand the mission of Epilepsy Currents.

Beginning in 2011, Epilepsy Currents will be self-published with the assistance of Allen Press. Self-publishing offers considerable savings but, more importantly, also allows much more flexibility in modifying format and content. You will notice that we have a refined new look.

The Senior Editors are pleased to introduce a new section to Epilepsy Currents. We now invite readers to submit letters to the editor, which may be published both in the print version and in the online version of the journal. These letters will typically be in response to a published commentary or review from a previous issue. We urge readers to submit such letters in a reasonably close temporal proximity to the original publication of the item. An original letter not associated with a previously published topic may be considered, but only if the Senior Editors feel that it will be of significant interest to the readers of the journal. Letters should not be longer than 450 words in length. If the letter relates to a previously published item, the editors will send the letter to the author of the original item, who will be invited to respond. Letters can be sent to lettersec@aesnet.org.

We, as Senior Editors, are very excited about this new element in Epilepsy Currents. We hope that this will make the journal more interactive, more lively, and will allow for important discourse within the community on controversial topics. We hope that you will enjoy the dialogue, both as writers and as readers.

\section{Gregory K. Bergey, MD}

Chief Editor, Clinical Science

Michael A. Rogawski, MD, PhD

Chief Editor, Basic Science

Jacqueline French, MD

Associate Editor, Clinical Science

Carl E. Stafstrom, MD, PhD

Associate Editor, Basic Science

\section{A New Policy for Disclosure of Competing Interests}

Epilepsy Currents published its first issue in September 2001, nearly a decade ago. In the intervening years, there has been increasing concern voiced by professionals and the public that competing interests may unduly influence the objectivity of authors and degrade the integrity of the biomedical research literature to the detriment of patients. It is now generally accepted that readers have a right to know of relevant competing interests and that transparency will enhance objectivity. To this end, many journals have adopted policies for the disclosure of competing interests. The approaches taken have varied from journal to journal (1). To reduce the burden on authors in complying with these diverse disclosure requirements, the International Committee of Journal Medical Editors (ICJME), a group of medical journal editors originally

Epilepsy Currents, Vol. 11, No. 1 (January/February) 2011 pp. 7-8

o American Epilepsy Society

OPEN $\odot$ ACCESS Freely available online constituted to define uniform requirements for manuscript submission, recommended a uniform set of disclosures, which was recently updated as a fill-in PDF form (2). Authors are asked to disclose the following types of relationships:

(1) financial support to the author or institution for the work being submitted; (2) relevant financial relationships in the biomedical arena outside the submitted work during the 36 months prior to submission; and (3) any other relationships or activities that could be perceived as relevant. Many high profile medical journals including the New England Journal of Medicine, JAMA, and Annals of Internal Medicine, now use this uniform disclosure form. The form itself is often provided to interested readers separately from the article, which has the advantage of allowing for complete disclosure without consuming space in the article itself.

When Epilepsy Currents was founded, expressions of public concern about the influence of conflicts of interest on biomedical research were much more muted than today. At the same time, Epilepsy Currents does not publish origi- 
nal research, so standards were not clear. In recent years, the visibility of Epilepsy Currents has increased and it has emerged as an important vehicle for interpreting epilepsy research and communicating diverse viewpoints on key concepts in the field. With its expanding stature has come the recognition that the journal should adopt best current practices regarding the disclosure of competing interests to fulfill its responsibilities to readers and ultimately to patients. Indeed, the editors recognize that objectivity and trust are ever more critical given the journal's unique educational role and the potential that information presented in the journal will inform clinical practice. Therefore, we will now require all authors to complete ICJME forms disclosing relevant competing interests. These forms will be available for public review on the AES web site. We are confident that this new policy will enhance trust in the journal and improve its utility in the advancement of epilepsy research and clinical care.

Michael A. Rogawski, MD, PhD

\section{References}

1 Blum JA, Freeman K, Dart RC, Cooper RJ. Requirements and definitions in conflict of interest policies of medical journals. JAMA 2009;302:2230-2234.

2 Drazen JM, Van der Weyden MB, Sahni P, Rosenberg J, Marusic A, Laine C, Kotzin S, Horton R, Hébert PC, Haug C, Godlee F, Frizelle FA, de Leeuw PW, DeAngelis CD. Uniform format for disclosure of competing interests in ICMJE journals. N Engl J Med 2009;361:18961897. 